\title{
Prevalence of Depression in Survivors of Acute Myocardial Infarction
}

\section{Review of the Evidence}

Brett D. Thombs, PhD, ${ }^{1,2}$ Eric B. Bass, MD, MPH, ${ }^{1,3,4,5}$ Daniel E. Ford, $M D^{1,2,3,4,5}$

Kerry J. Stewart, ED, ${ }^{1,3}$ Konstantinos K. Tsilidis, MPH, ${ }^{1,4}$ Udita Patel, MPH, ${ }^{1}$ James A. Fauerbach, PhD, 1,2 David E. Bush, MD, ${ }^{1,3}$ Roy C. Ziegelstein, MD ${ }^{1,3}$

'Johns Hopkins University Evidence-based Practice Center, Johns Hopkins University School of Medicine, Baltimore, Md, USA;

${ }^{2}$ Department of Psychiatry and Behavioral Sciences, Johns Hopkins University School of Medicine, Baltimore, Md, USA;

${ }^{3}$ Department of Medicine, Johns Hopkins University School of Medicine, Baltimore, Md, USA; ${ }^{4}$ Department of Epidemiology, Johns Hopkins Bloomberg School of Public Health, Baltimore, Md, USA; ${ }^{5}$ Department of Health Policy and Management, Johns Hopkins Bloomberg School of Public Health, Baltimore, Md, USA.

OBJECTIVES: To assess the prevalence and persistence of depression in patients with acute myocardial infarction (AMI) and the relationship between assessment modality and prevalence.

DATA SOURCES: MEDLINE ${ }^{\mathbb{R}}$, Cochrane, CINAHL $^{\circledR}$, PsycINFO $^{\circledR}$, and EMBASE $^{\circledR}$.

REVIEW METHODS: A comprehensive search was conducted in March 2004 to identify original research studies published since 1980 that used a standardized interview or validated questionnaire to assess depression. The search was augmented by hand searching of selected journals from October 2003 through April 2004 and references of identified articles and reviews. Studies were excluded if only an abstract was provided, if not in English, or if depression was not measured by a validated method.

RESULTS: Major depression was identified in 19.8\% (95\% confidence interval [CI] $19.1 \%$ to $20.6 \%$ ) of patients using structured interviews $(N=10,785,8$ studies). The prevalence of significant depressive symptoms based on a Beck Depression Inventory score $\geq 10$ was $31.1 \%$ (CI $29.2 \%$ to $33.0 \%$; $N=2,273,6$ studies), using a Hospital Anxiety and Depression Scale (HADS) score $\geq 8 \%, 15.5 \%$ (CI $13.2 \%$ to $18.0 \%$; $N=863,4$ studies), and with a HADS score $\geq 11 \%, 7.3 \%$ (CI $5.5 \%$ to $9.3 \% ; N=830,4$ studies). Although a significant proportion of patients continued to be depressed in the year after discharge, the limited number of studies and variable follow-up times precluded specification of prevalence rates at given time points.

CONCLUSIONS: Depression is common and persistent in AMI survivors. Prevalence varies depending on assessment method, likely reflecting treatment of somatic symptoms.

KEY WORDS: myocardial infarction; depression; prevalence; systematic review.

DOI: $10.1111 /$ j.1525-1497.2005.00269x.

J GEN INTERN MED 2006; 21:30-38.

I ncreasing attention has been focused on mood disturbance in patients recovering from an acute myocardial infarction (AMI), especially since it was first reported that depression was associated with increased mortality after AMI. ${ }^{1}$ More recent studies have reported a similar association, ${ }^{2-6}$ although some authors have found that this association is not significant if other predictors of mortality are taken into account,,${ }^{7,8}$ or if one adjusts for potentially confounding symptoms, like fatigue, that may be common to depression and heart disease. ${ }^{9} \mathrm{~A}$

The authors have no conflicts of interest to report.

Address correspondence and reprint requests to Dr. Ziegelstein: Department of Medicine, B-1-North, Johns Hopkins Bayview Medical Center, 4940 Eastern Avenue, Baltimore, MD 21224-2780 (e-mail: rziegel@jhmi.edu). meta-analysis published in 2004 found that depression is associated with cardiac and all-cause mortality in post-AMI patients after controlling for other predictors. ${ }^{10}$ A second 2004 meta-analysis reported similar results, but focused more broadly on patients with coronary heart disease rather than specifically on patients with AMI. ${ }^{11}$ The authors of a 2005 systematic review, however, concluded that quality issues, such as the use of nonvalidated measurements and insufficient power, made it difficult to draw unambiguous conclusions about the association between depression and post-AMI mortality. $^{12}$

Acute myocardial infarction practice guidelines recommend that the psychosocial status of patients be evaluated, "including inquiries regarding symptoms of depression." 13 These guidelines, however, do not recommend procedures for assessing depression or distinguishing symptoms of depression from those of heart disease. Symptoms characteristically associated with depression may occur as a normal reaction to the AMI or to the hospitalization itself, complicating diagnosis. ${ }^{14-16}$ The most commonly used assessment methods for identifying patients with depression after AMI are structured clinical interviews ${ }^{17-19}$ and questionnaires, particularly the Beck Depression Inventory (BDI) ${ }^{20}$ and the Hospital Anxiety and Depression Scale (HADS). ${ }^{21}$ Van Melle et al. ${ }^{10}$ reported prevalence data from over 15 distinct cohorts in their systematic review of the association of depression with mortality and cardiovascular events. As the focus of their study was on this association rather than on prevalence, their sample included fewer than half of the studies from the peer-reviewed literature that report prevalence of post-AMI depression within 1 month of the index event. No studies have systematically reviewed the prevalence of depression among post-AMI patients or have investigated the effect of assessment modality on reported prevalence rates.

This systematic review of the literature addresses the following questions: (1) What is the prevalence of depression among patients hospitalized for AMI? (2) How common are clinically significant symptoms of depression among patients hospitalized for AMI? (3) How do symptoms of depression, if present at the time of hospitalization, evolve over time? and (4) What is the relationship between assessment modality and reported prevalence? The review was part of a comprehensive evidence report carried out to address these and other questions related to post-AMI depression. ${ }^{22}$

Manuscript received April 5, 2005

Initial editorial decision June 13, 2005

Final acceptance August 16, 2005 


\section{METHODS}

\section{Search Strategy}

The MEDLINE ${ }^{\circledR}$, Cochrane, CINAHL $^{\circledR}$, PsycINFO ${ }^{\circledR}$, and EMBASE $^{\circledR}$ databases were searched for articles published between 1980 and March 2004. Search strategies and terms are found in Appendix A. Hand searching was carried out on 16 selected journals (see Appendix B) through April 2004, and on references of reviews and eligible articles. No searching was carried out for data from unpublished articles. We used ProCite ${ }^{\circledR}$ reference management software to create a database of reference material identified through an electronic search for relevant guidelines and reviews, through discussions with experts, and through the article review process.

\section{Study Selection}

Two investigators independently evaluated studies for inclusion with discrepancies resolved by consensus. Studies published since 1980 with original human data that used a standardized interview or validated questionnaire to assess depression were included. When multiple articles were published on the same study cohort, the most relevant article was included. Articles were excluded if they consisted of case series or case reports, were not in English, if only a meeting abstract was provided, if depression was not measured by a validated method, or if data was not reported on the timing of the depression assessment relative to the myocardial infarction (MI). Studies with mixed populations were included if data on MI patients were reported separately. Author and journal names were not masked as masking does not appear to significantly influence inclusion and exclusion decisions. ${ }^{23}$

\section{Data Extraction and Quality Assessment}

Two investigators independently extracted data, reconciling differences by face-to-face meeting and consensus. Data extraction forms were developed from consensus among the investigative team regarding the items that were most important for describing the characteristics of each study, and summarizing study results. The evidence-grading scheme followed the approach recommended by the International GRADE Working Group, and reflected the quantity, quality, and consistency of the evidence. ${ }^{24}$ Assessment of the methodological quality of each study was performed independently by each reviewer and reflected the study's representativeness, assessment protocol, outcomes and follow-up, statistical analysis, and degree of conflict of interest.

\section{Definition and Assessment of Depression}

Depression was defined as "symptoms meeting established clinical threshold criteria for depression as measured by validated questionnaires or standardized psychiatric interviews." Questionnaires measure symptoms of depression whereas standardized interviews use Diagnostic and Statistical Manual (DSM) criteria to establish a diagnosis. This report refers to "validated questionnaires or rating scales." Although all included studies use instruments validated in at least 1 patient group, little systematic validation has been carried out specifically in AMI patients. ${ }^{22}$ In addition, the manner in which "clinical threshold criteria" is interpreted varies considerably across studies. For example, 1 study used a score $\geq 8$ on the depression subscale of the HADS to report a prevalence of "clinically significant levels of depression,"25 whereas another used $\geq 11$ to denote "clinical levels of depression." ${ }^{26}$ Three other studies referred to a scores from 8 to 10 as "possibly clinically significant" or "borderline" depression and a score $\geq 11$ as "probably clinically significant" depression. ${ }^{27-29}$

The second part of this inquiry addressed the percentage of patients with post-AMI depression in the hospital who continued to be depressed 1 month or longer after the index AMI. A number of studies reported overall prevalence data at hospitalization and follow-up, but did not report the prevalence of depression after discharge among the group initially depressed. Other studies just reported data 1 month or longer after AMI. Despite not addressing the persistence of depression among those depressed during hospitalization, data from these studies are reported as an indicator of the overall prevalence of depression at different points post-discharge.

\section{Data Synthesis}

Weighted in-hospital prevalence rates were calculated for all groups of studies that used an identical assessment method and cutoff criterion. Ninety-five percent confidence intervals (CI) for these estimates were calculated using the bootstrap meth$\mathrm{od}^{30,31}$ with 1,000 resamples. Multiple comparisons between pairs of weighted prevalence rates across assessment methods and criteria were conducted using Hochberg's Sequential Meth$\mathrm{od}^{32}$ to maintain the family-wise error rate at $p<.05$.

\section{RESULTS}

\section{Search Results}

The search process for the entire post-AMI depression review ${ }^{22}$ identified 3,770 unique titles. During the title and abstract reviews, 2,597 and 825 citations were excluded, respectively. Of the remaining articles, 128 were reviewed for prevalence of depression during hospitalization, and 56 for prevalence 1 month or more post-AMI. After the final article review, 24 articles were included for prevalence during hospitalization (Table 1). Four reported data on the persistence of depression in those depressed during hospitalization (Table 2), and 18 on prevalence 1 month or more after AMI (Table 3).

\section{Prevalence of Depression Among Patients Hospitalized for AMI}

Twenty-four studies published between 1986 and 2004, which examined 14,326 patients, were included for in-hospital depression (Table 1). The studies ranged in size from 37 to 9,279 subjects. Mean age ranged from 51 to 68 years old and the percentage of males from $58 \%$ to $100 \%$. Of the 24 included articles, 8 used a standardized interview for the diagnosis of depression (e.g., Structured Clinical Interview for DSM [SCID] or Diagnostic Interview Schedule [DIS]). ${ }^{6,8,33-38}$ Seventeen studies used validated questionnaires or rating scales, including the BDI, $3,6,39-42,44,47,48$ the Hamilton Rating Scale for Depression, ${ }^{41,43}$ the HADS, ${ }^{25-29}$ the Montgomery-Asberg Depression Rating Scale, ${ }^{45}$ or the Holland Sgroi Anxiety Depression Scale. ${ }^{46}$

The prevalence of depression ranged from $16 \%$ to $45 \%$ in the 8 studies that used a structured clinical interview. The largest of these studies, the Enhancing Recovery in Coronary Heart Disease Patients (ENRICHD) study, ${ }^{38}$ examined 9,279 


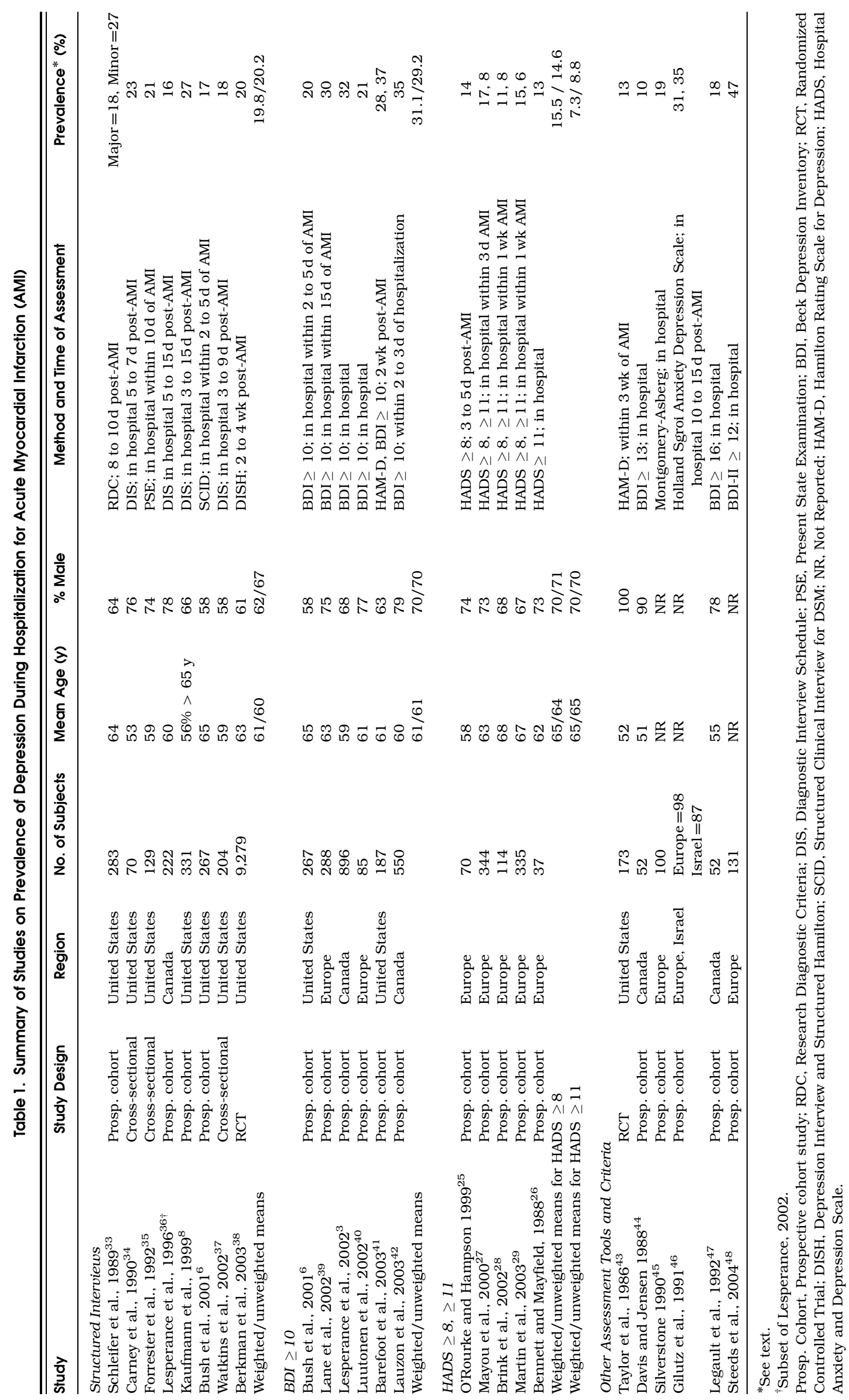


Table 2. Summary of Studies on Prevalence of Depression 1 month or More PostAcute Myocardial Infarction (AMI) for Patients Identified in Hospital

\begin{tabular}{|c|c|c|c|c|c|c|c|c|c|c|c|}
\hline \multirow[t]{2}{*}{ Study } & \multirow{2}{*}{$\begin{array}{l}\text { Study } \\
\text { Design }\end{array}$} & \multirow[t]{2}{*}{ Region } & \multirow{2}{*}{$\begin{array}{l}\text { Mean } \\
\text { Age }\end{array}$} & \multirow{2}{*}{$\begin{array}{c}\% \\
\text { Male }\end{array}$} & \multirow{2}{*}{ Method } & \multicolumn{3}{|c|}{ In Hospital } & \multicolumn{3}{|c|}{ Follow-up } \\
\hline & & & & & & $\begin{array}{c}\text { No. of } \\
\text { Subjects }\end{array}$ & $\begin{array}{c}\text { Time of } \\
\text { Assessment }\end{array}$ & $\begin{array}{c}\text { Prevalence } \\
(\%)\end{array}$ & $\begin{array}{c}\text { No. of } \\
\text { Subjects }\end{array}$ & $\begin{array}{c}\text { Time of } \\
\text { Assessment }\end{array}$ & $\begin{array}{l}\% \text { of Patients with } \\
\text { Depression in } \\
\text { Hospital and } \\
\text { at Follow-up }\end{array}$ \\
\hline $\begin{array}{l}\text { Schleifer } \\
\quad \text { et al., } 1989^{33}\end{array}$ & $\begin{array}{l}\text { Prospective } \\
\text { Cohort }\end{array}$ & $\begin{array}{l}\text { United } \\
\text { States }\end{array}$ & 63 & 64 & $\mathrm{RDC}$ & 283 & $\begin{array}{l}8 \text { to } 10 \mathrm{~d} \\
\text { post-AMI }\end{array}$ & $\begin{array}{l}\text { Major }=18 \\
\text { Minor }=27\end{array}$ & 190 & $3 \mathrm{mo}$ & $\begin{array}{l}\text { Major in hospital: } \\
\text { Major }=37 \\
\text { Minor }=37 \\
\text { Minor in hospital: } \\
\text { Major }=16 \\
\text { Minor }=22\end{array}$ \\
\hline $\begin{array}{l}\text { Lesperance } \\
\text { et al., } 1996^{36}\end{array}$ & $\begin{array}{l}\text { Prospective } \\
\text { Cohort }\end{array}$ & Canada & 60 & 78 & DIS & 222 & $\begin{array}{l}5 \text { to } 15 d \\
\text { post-AMI }\end{array}$ & 16 & $\begin{array}{l}204 \\
182\end{array}$ & $\begin{array}{c}6 \mathrm{mo} \\
12 \mathrm{mo}\end{array}$ & $\begin{array}{l}48 \\
43\end{array}$ \\
\hline $\begin{array}{l}\text { Lauzon } \\
\text { et al., } 2003^{42}\end{array}$ & $\begin{array}{l}\text { Prospective } \\
\text { Cohort }\end{array}$ & Canada & 60 & 80 & $\mathrm{BDI} \geq 10$ & 550 & $\begin{array}{l}\text { Within } 2 \text { to } \\
3 \mathrm{~d} \text { of } \\
\text { hospitalization }\end{array}$ & 35 & 466 & $30 \mathrm{~d}$ & 70 \\
\hline $\begin{array}{l}\text { Davis and } \\
\text { Jensen, } 1988^{44}\end{array}$ & $\begin{array}{l}\text { Prospective } \\
\text { Cohort }\end{array}$ & Canada & 51 & 90 & $\mathrm{BDI} \geq 13$ & 52 & In hospital & 10 & 52 & 6 to $8 w k$ & 60 \\
\hline
\end{tabular}

RDC, Research Diagnostic Criteria; DIS, Diagnostic Interview Schedule for DSM-III; BDI, Beck Depression Inventory.

patients and reported a prevalence of $20 \%$. ENRICHD included patients with low social support and/or major depression, but only those with major depression were included in this analysis. The weighted prevalence for all 8 studies was $20.5 \%$ $(N=10,785$; CI $19.8 \%$ to $21.3 \%)$. These studies differed in terms of which diagnoses were identified and reported, the duration of symptoms required to establish the diagnosis, and the timing of the assessment relative to the AMI. Four studies only reported the diagnosis of major depression, ${ }^{8,34,36,37} 2$ studies reported major depression and dysthymia, ${ }^{6,35} 1$ study included major and minor depression, ${ }^{33}$ and 1 study included major depression, minor depression and dysthymia. ${ }^{38}$ Three studies did not have a symptom duration criterion, ${ }^{8,35,36} 2$ studies used a 7 -day criterion, ${ }^{33,37}$ and 1 study required 7 days for repeat episodes, but 14 days for new diagnoses. ${ }^{38}$ Two studies required the presence of symptoms for 2 weeks prior to the AMI. ${ }^{6,34}$ Timing of assessment ranged from $2-5$ days ${ }^{6}$ to 14-15 days post-AMI. ${ }^{8,36,38}$ The study that reported the highest prevalence of depression ${ }^{33}$ reported a prevalence of $18 \%$ for major depression and $27 \%$ for minor depression, for a total of $45 \%$. If only major depression were included for this study, which appears to be a reasonable approach, the range of prevalence rates for studies that used structured clinical interviews would be $16 \%$ to $27 \%$, and the weighted prevalence rate would be $19.8 \%$ (CI $19.1 \%$ to $20.6 \%$ ).

\section{Symptoms of Depression Among Patients Hospitalized for AMI}

In the 17 studies that used a validated questionnaire or rating scale, $10 \%$ to $47 \%$ of patients had clinically significant symptoms of depression. Instruments and threshold criteria, however, varied substantially. Of the 9 studies that used the BDI, 6 used a score of $\geq 10$ to indicate "at least mild-to-moderate symptoms of depression,"3,6,39,42 and reported a prevalence range of $20 \%$ to $37 \%$. The weighted prevalence was $31.1 \%$ ( $N=2,273$; CI $29.2 \%$ to $33.0 \%$ ).

In the 4 studies that used a HADS score of $\geq 8,{ }^{25,27-29}$ prevalence ranged from $11 \%$ to $17 \%$. The weighted prevalence was $15.5 \%$ ( $N=863$; CI $13.2 \%$ to $18.0 \%)$. In the 4 studies that used a HADS $\geq 11,{ }^{26-29}$ the prevalence range was from $6 \%$ to $13 \%$. If 1 study with only 37 subjects $^{26}$ is removed, the range is from $6 \%$ to $8 \%$. The weighted prevalence was $7.3 \%(N=830$; CI $5.5 \%$ to $9.3 \%)$.

Thus, prevalence rates were similar among studies that used the same assessment method and cutoff criterion (Fig. 1). There were significant differences, however, between all pairs of weighted prevalence rates. Overall evidence quality for the studies was rated as medium. Detailed quality ratings are available in the full evidence report. ${ }^{22}$

\section{Persistence of Depression After AMI}

Only 4 studies addressed the persistence of depression in patients diagnosed during hospitalization for AMI (Table 2). ${ }^{33,36,42,44}$ These studies reported follow-up data at 30 days, ${ }^{42} 6$ to 8 weeks, ${ }^{44} 3$ to 4 months, ${ }^{33}$ and 6 and 12 months after AMI. ${ }^{36}$ Only 1 of these studies reported data on the number of patients who were referred for or received treatment for depression. ${ }^{36}$

Davis and Jensen ${ }^{44}$ found that of the 5 of 52 patients initially having a BDI score of 13 or higher, 3 of the $5(60 \%)$ were still depressed 6 to 8 weeks later. Schleifer et al. ${ }^{33}$ reported inhospital and follow-up data on 190 patients, 30 of whom had major depression and 51 of whom had minor depression during the initial hospitalization based on a SCID. ${ }^{17}$ Of the 30 patients with major depression during the initial hospitalization, more than $70 \%$ had either major depression or minor depression at follow-up. Of the 30, 11 (36.7\%) had major depression 3 to 4 months later and 11 (36.7\%) had minor depression for a total of 22 out of 30 (73.3\%). Lauzon et al. ${ }^{42}$ reported prevalence data on 550 patients during the AMI hospitalization and 466 at 30-day follow-up. Of the patients with a BDI score $\geq 10$ during hospitalization, $70 \%$ continued to be depressed at 30 days. Lesperance et al. ${ }^{36}$ studied 222 patients during the AMI hospitalization and at 6 and 12 months post-AMI. Of the patients with major depression at baseline using the DIS, ${ }^{19} 48 \%$ and $43 \%$ continued to have major depression at 6 and 12 months, respectively. Thus, in these 4 studies, a majority of patients with depression during 


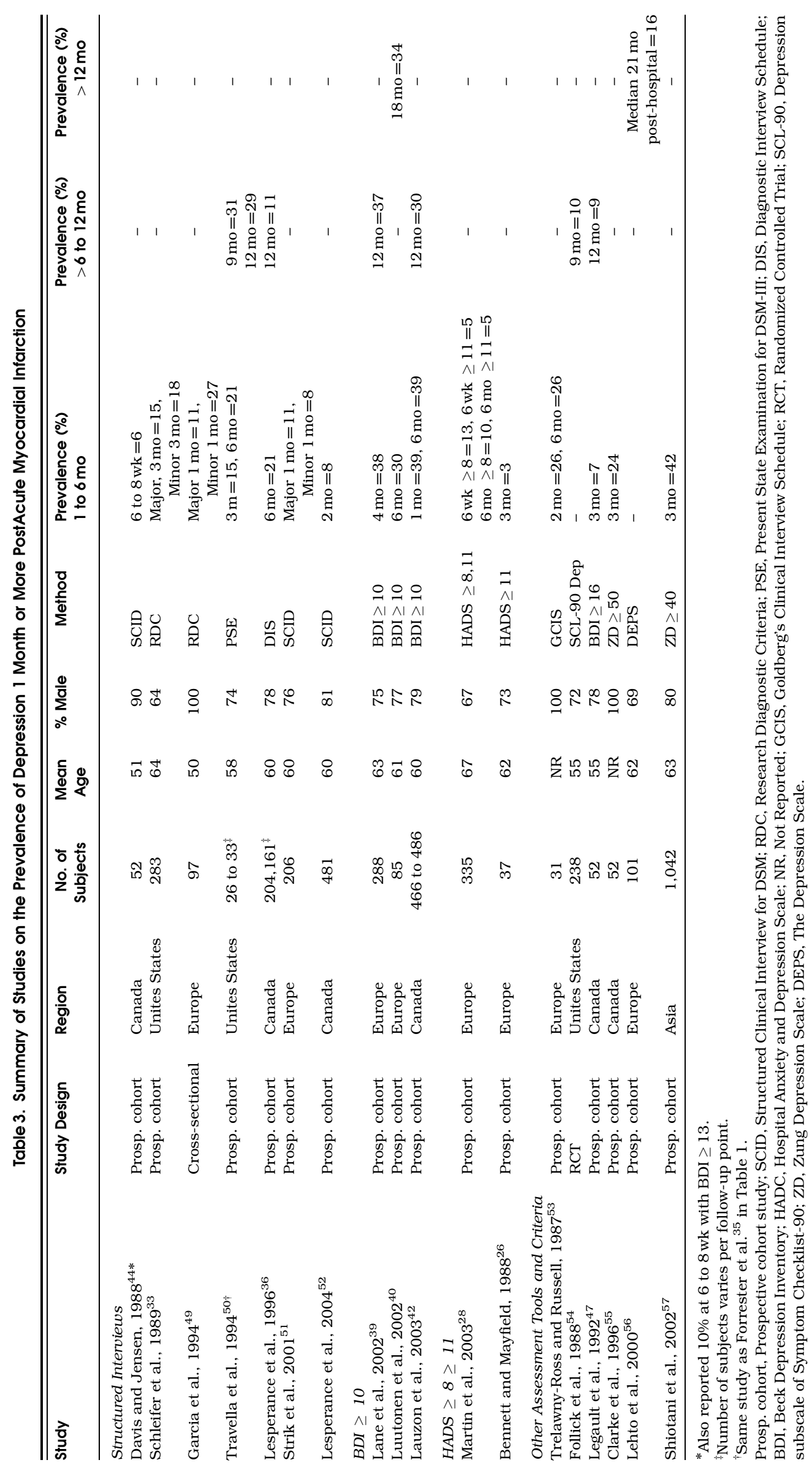




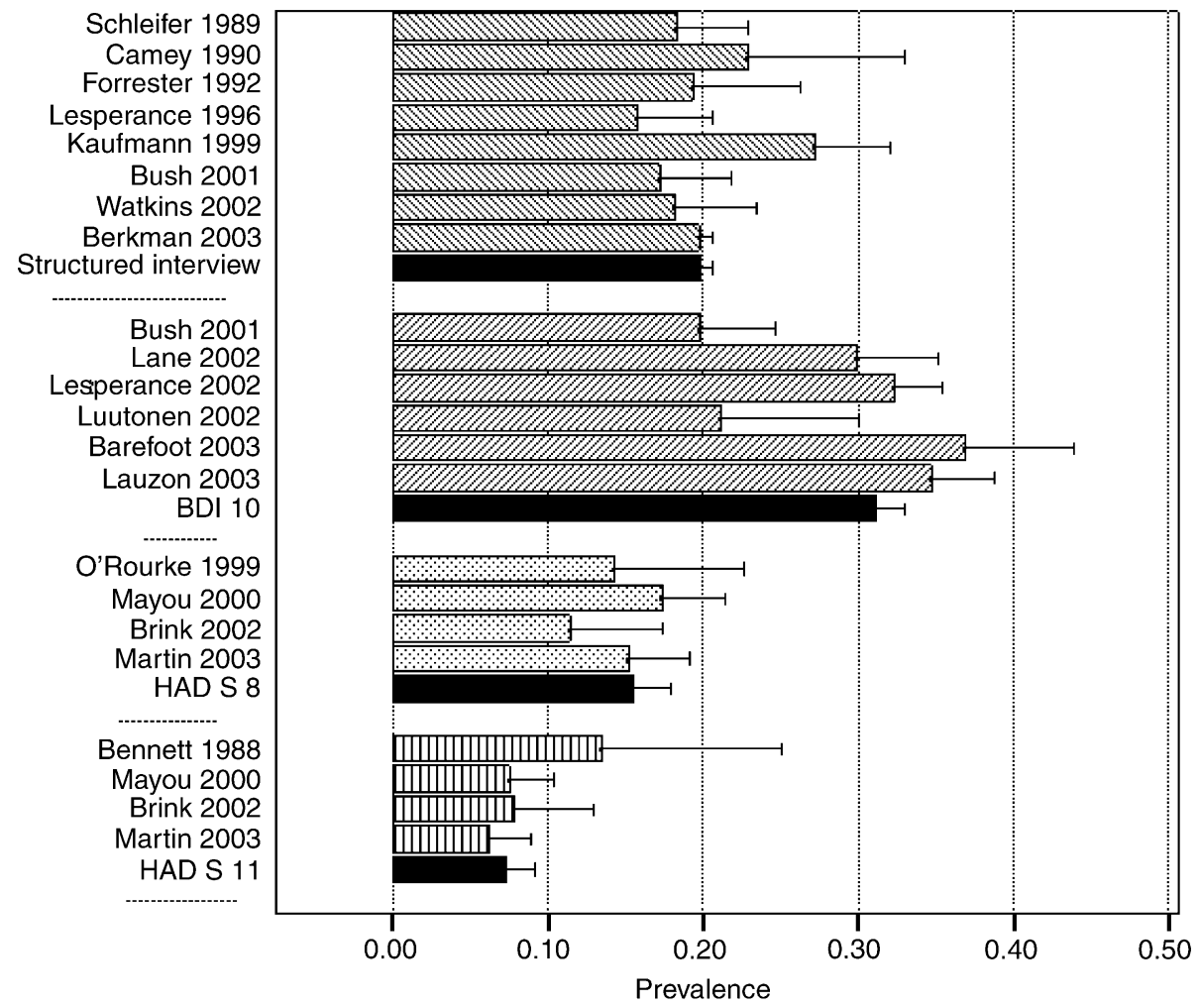

FIGURE 1. Prevalence of depression during hospitalization for acute myocardial infarction. The reported prevalence of depression in included studies is depicted, along with the error bars indicating $95 \%$ confidence intervals. Shown in forward crosshatched bars are the prevalence rates in studies that used structured interviews (top group). Shown in backward crosshatched bars are the prevalence rates using a Beck Depression Inventory score of 10 or greater (second group from top). Shown in black dots on a white background are the prevalence rates using a Hospital Anxiety and Depression Scale (HADS) score of 8 or greater (second group from bottom). Shown in vertical bars are prevalence rates using a HADS score of 11 or greater (bottom group). Weighted group prevalence rates are shown in solid black bars beneath each group.

the initial hospitalization remained depressed when assessed 1 to 12 months later.

A total of 18 studies, including the 4 above, reported prevalence data 1 month or longer after AMI without necessarily distinguishing persistent depression from new incidence and remission patterns. Of the 18 studies, 7 employed commonly used standardized clinical interviews for the diagnosis of depression, ${ }^{33,36,44,49-52} 11$ used validated questionnaires or rating scales such as the BDI, ${ }^{39,40,42,44,47}$ the Zung Depression Rating Scale (ZDS), ${ }^{55,57}$ the HADS, ${ }^{26,28}$ the SCL-90 Depression Subscale, ${ }^{54}$ or the Depression Scale, ${ }^{56}$ and one used Goldberg's Clinical Interview Schedule ${ }^{53}$ (Table 3). The studies varied widely in terms of method and timing of assessment and reported prevalence rates. Nevertheless, the reported prevalence of major depression or potentially significant symptoms of depression in these studies is much higher than the generally accepted $5 \%$ prevalence in the general population. ${ }^{58}$

\section{DISCUSSION}

This is the first systematic review of the literature examining the prevalence of depression after AMI with data on more than 14,000 patients. Based on 10,785 patients assessed using a structured clinical interview, major depression was present in approximately 1 of 5 patients hospitalized for AMI. Based on 2,273 patients assessed using a $\mathrm{BDI}^{20}$ score $\geq 10$, approximately 1 of 3 patients hospitalized for AMI had "at least mild- to-moderate symptoms of depression." A lower prevalence of depressive symptoms meeting threshold criteria suggesting clinical significance was reported in studies using the HADS, ${ }^{21}$ for both thresholds designating "possibly clinically significant depression" ( $\geq 8$; approximately 1 in 6 patients) or "probably clinically significant depression" ( $\geq 11$; approximately 1 in 13 patients). Only 4 studies reported the proportion of patients with major depression or clinically significant symptoms of depression during the AMI hospitalization that remained depressed after hospital discharge. In these studies, which included 1,107 patients during the AMI hospitalization and 912 patients at follow-up, depression during the AMI hospitalization persisted in about half to two-thirds of initially depressed individuals in the first 1 to 12 months after discharge. The $19.8 \%$ prevalence of depression in patients hospitalized for AMI is higher than the possibly conservative rate of major depression in the general population as reported by the National Comorbidity Study (5\%), ${ }^{58}$ in primary care (5\% to $\left.10 \%\right),{ }^{59}$ or in other inpatient medical settings (6\% to $14 \%) .{ }^{59}$ It is closer to the prevalence rates reported among patients with a stroke (20\% to $30 \%) .{ }^{60-63}$

The reported prevalence of depression using a structured clinical interview (19.8\%) was higher than the prevalence of possible $(15.5 \%)$ or probable $(7.3 \%)$ clinical depression using the HADS and lower than the prevalence of "at least mild-tomoderate symptoms of depression" using the BDI (31.1\%). These differences do not appear related to population charac- 
teristics, which were similar across all assessment method groups (Table 1), or to sample size, regional differences, or evidence quality. These discrepancies appear to reflect some of the challenges in evaluating symptoms of depression among patients hospitalized with acute medical illness. Somatic symptoms used to diagnose depression can be difficult to distinguish from symptoms secondary to medical illness or its treatment. ${ }^{15,64-66}$ Koenig et al. ${ }^{66}$ documented similar variability in the reported prevalence of depression among medically ill patients based on characteristics of the method of assessment.

The DSM-IV ${ }^{67}$ states that symptoms "accounted for by a general medical condition" should not be counted toward a diagnosis of major depression. There are no explicitly defined paradigms, however, for determining the origin of somatic symptoms. Thus, whether to attribute them to depression or not is typically left to interviewer judgment. The HADS does not include any questions about somatic symptoms. ${ }^{68}$ By contrast, 7 of the 21 items on the BDI assess somatic symptoms of depression with no reference to origin. ${ }^{20}$ It is therefore not surprising that the prevalence of possible or probable clinical depression using the HADS was lower than either the prevalence of major depression with a structured clinical interview or the prevalence of potentially significant depressive symptoms as assessed by the BDI.

Limitations of this review include the wide variations in the designs of the studies from which data was synthesized. Although results were relatively homogeneous within assessment modalities and threshold criteria, there was marked heterogeneity in study size, in-hospital and follow-up assessment timing, symptom duration criteria utilized, and diagnostic inclusiveness in studies that used standardized interviews. In addition, the review did not include abstracts, nonpublished studies, or studies published in non-English language journals. Although there does not appear to be a relationship between prevalence and sample size of the studies, we cannot rule out selection biases.

There are several reasons why it seems appropriate to screen for depression during the AMI hospitalization. Depression may have a greater effect on quality of life and physical limitation in patients with coronary disease than traditionally determined measures of cardiac function. ${ }^{69}$ This effect is likely to persist for at least several months, since depression that is present during the AMI hospitalization does not resolve in a substantial proportion of patients based on the few studies that have addressed this issue. Depression would be important to identify in AMI patients if it were shown that patients should be treated differently than those who are not depressed. For example, patients with depression after AMI have increased platelet activation ${ }^{70}$ and poor adherence to recommended therapy, ${ }^{71}$ raising the possibility that these patients should receive more aggressive antiplatelet therapy or focused adherence-enhancing initiatives. Although the effect of these strategies has not yet been examined, proper identification of patients with depression during the AMI hospitalization is critical if these questions are to be appropriately addressed. Some have argued that depression should be identified during the AMI hospitalization because depressed patients have a higher risk of morbidity and mortality after AMI. ${ }^{1,2,4}$ Two recent large, randomized controlled trials assessed whether treatment of depression affects prognosis in AMI patients with depression, ${ }^{33,72}$ and neither definitively demonstrated that treatment of depression alters cardiovascular prognosis of AMI patients.
It would be unfortunate if these results were to lead health care providers to turn their attention away from depression in the AMI setting, however, as it is widely accepted that depression is common and underrecognized in many clinical settings. A patient hospitalized for AMI provides an opportunity for the diagnosis and treatment of health conditions other than the individual's cardiac condition.

This systematic review suggests that if clinicians assess for symptoms of depression as endorsed by AMI practice guidelines, ${ }^{13}$ results will differ considerably depending on method of assessment. It appears reasonable to screen patients with a validated questionnaire, and then to assess patients who screen positive using a structured clinical interview. This assessment can be further refined by re-examining the patient several weeks after discharge. At first glance, based on reported prevalence rates alone, it would appear that the BDI is a more appropriate initial screening instrument than the HADS as it identifies more potentially depressed patients during the AMI hospitalization, a desirable quality in a screening instrument. Although a BDI score of 10 or above may overdiagnose depression, evidence suggests that patients with BDI scores at or above this threshold soon after an AMI have higher morbidity ${ }^{41}$ and mortality ${ }^{3,5,6}$ risks than those patients who endorse fewer symptoms of depression on this questionnaire. These findings, coupled with the "dose response" of BDI scores as predictors of risk after $\mathrm{AMI}^{3,6}$ suggest that the BDI is the preferred mode of assessment in this setting. We believe that further research studies are warranted to compare the performance characteristics of the BDI to other depression screening instruments in patients who are hospitalized with AMI; to assess whether alternative assessment methods, such as administering only the nonsomatic items on the BDI, produce improved results; and to examine which patients so identified are likely to remain depressed after discharge from the hospital. Until these studies are performed, we suggest that clinicians consider using the BDI when following current practice guidelines that recommend assessing patients for symptoms of depression after an AMI. ${ }^{13}$ Patients who score 10 or above on the BDI should then be evaluated by a clinical psychologist or psychiatrist.

Although this systematic review did not address the ideal timing of post-AMI depression screening, a reasonable strategy would be to use the BDI during the initial hospitalization when the patient is readily accessible. If a patient has symptoms of depression (BDI $\geq 10$ ), the possibility that depression may impact the patient's recovery could be discussed with the patient and other appropriate individuals in collaboration with the patient. If the patient notes that negative emotions are adversely affecting self-care and ability to function or if the patient has thoughts of self-harm, a referral to a mental health provider should be facilitated. In cases where an immediate referral is not made, the patient could be reassessed by BDI screening 2 weeks after discharge. If the patient still scores $\geq 10$, referral to a mental health provider for a formal assessment should be arranged; somatic symptoms present at this point should be assumed to be related to depression rather than to the patient's cardiac condition, particularly if the cardiologist indicates that the latter has stabilized.

This article is based on research conducted by the Johns Hopkins University Evidence-based Practice Center under contract 
to the Agency for Healthcare Research and Quality (Contract No. 290-02-0018), Rockville, Md. The authors of this article are responsible for its contents, including any clinical or treatment recommendations. No statement in this article should be construed as an official position of the Agency for Healthcare Research and Quality or of the U.S. Department of Health and Human Services. We thank Captain Ernestine Murray for her support as the Task Order Officer for this project.

\section{REFERENCES}

1. Frasure-Smith N, Lesperance F, Talajic M. Depression following myocardial infarction. Impact on 6-month survival. JAMA. 1993;270:181925.

2. Carney RM, Blumenthal JA, Catellier D, et al. Depression as a risk factor for mortality after acute myocardial infarction. Am J Cardiol. 2003;92:1277-81.

3. Lesperance F, Frasure-Smith N, Talajic M, Bourassa MG. Five-year risk of cardiac mortality in relation to initial severity and one-year changes in depression symptoms after myocardial infarction. Circulation. 2002;105: 1049-53.

4. Welin C, Lappas G, Wilhelmsen L. Independent importance of psychosocial factors for prognosis after myocardial infarction. J Intern Med. 2000;247:629-39.

5. Frasure-Smith N, Lesperance F, Talajic M. Depression and 18-month prognosis after myocardial infarction. Circulation. 1995;91:999-1005.

6. Bush DE, Ziegelstein RC, Tayback M, et al. Even minimal symptoms of depression increase mortality risk after acute myocardial infarction. Am J Cardiol. 2001;88:337-41.

7. Ladwig KH, Kieser M, Konig J, Breithardt G, Borggrefe M. Affective disorders and survival after acute myocardial infarction. Results from the post-infarction late potential study. Eur Heart J. 1991;12:959-64.

8. Kaufmann MW, Fitzgibbons JP, Sussman EJ, et al. Relation between myocardial infarction, depression, hostility, and death. Am Heart J. 1999; 138:549-54.

9. Irvine J, Baker B, Smith J, et al. Poor adherence to placebo or amiodarone therapy predicts mortality: results from the CAMIAT study. Canadian Amiodarone Myocardial Infarction Arrhythmia Trial. Psychosom Med. 1999;61:566-75.

10. van Melle JP, de Jonge P, Spijkerman TA, et al. Prognostic association of depression following myocardial infarction with mortality and cardiovascular events: a meta-analysis. Psychosom Med. 2004;66:814-22.

11. Barth J, Schumacher M, Herrmann-Lingen C. Depression as a risk factor for mortality in patients with coronary heart disease: a meta-analysis. Psychosom Med. 2004;66:802-13.

12. Sorensenf C, Friis-Hasche E, Haghfelt T, Bech P. Postmyocardial infarction mortality in relation to depression: a systematic critical review. Psychother Psychosom. 2005;74:69-80.

13. Antman EM, Anbe DT, Armstrong PW, et al. ACC/AHA guidelines for the management of patients with ST-elevation myocardial infarction; A report of the American College of Cardiology/American Heart Association Task Force on Practice Guidelines (committee to revise the 1999 guidelines for the management of patients with acute myocardial infarction). J Am Coll Cardiol. 2004;44:E1-211.

14. Cavanaugh S, Clark DC, Gibbons RD. Diagnosing depression in the hospitalized medically ill. Psychosomatics. 1983;24:809-15.

15. Morrison MF, Kastenberg JS. Differentiation of secondary from primary mood disorders: controversies and consensus. Semin Clin Neuropsychiatr. 1997;2:232-43.

16. Sutor B, Rummans TA, Jowsey SG, et al. Major depression in medically ill patients. Mayo Clin Proc. 1998;73:329-37.

17. First MB, Spitzer RL, Gibbon M, Williams J. Structured Clinical Interview for DSM-IV Axis I Disorders-Patient Edition (SCID-I/P, Version 2.0). New York: Biometrics Research Department, New York State Psychiatric Institute; 1996.

18. Spitzer RL, Endicott J, Robins E. Research Diagnostic Criteria: rationale and reliability. Arch Gen Psychiatr. 1978;35:773-82.

19. Robins LN, Helzer JE, Croughan J, Ratcliff KS. National Institute of Mental Health Diagnostic Interview Schedule. Its history, characteristics, and validity. Arch Gen Psychiatr. 1981;38:381-9.

20. Beck AT, Steer RA, Garbin MG. Psychometric properties of the Beck Depression Inventory: twenty-five years of evaluation. Clin Psychol Rev. 1988;8:77-100.

21. Zigmond AS, Snaith RP. The Hospital Anxiety and Depression Scale. Acta Psychiatr Scand. 1983;67:361-70.
22. Bush DE, Ziegelstein RC, Patel UV, et al. Post-myocardial infarction depression. Evidence Rep Technol Assess (Summ). 2005;1-8.

23. Berlin JA. Does blinding of readers affect the results of meta-analyses? University of Pennsylvania Meta-Analysis Blinding Study Group. Lancet. 1997;350:185-6.

24. Atkins D, Eccles M, Flottorp S, et al. Systems for grading the quality of evidence and the strength of recommendations I: critical appraisal of existing approaches. The GRADE working group. BMC Health Serv Res. 2004; $4: 38$.

25. O'Rourke Á, Hampson SE. Psychosocial outcomes after an MI: an evaluation of two approaches to rehabilitation. Psychol, Health Med. 1999;4:393-402.

26. Bennett P, Mayfield T. Mood and behaviour change following first myocardial infarction. Coronary Health Care. 1998;2:210-4.

27. Mayou RA, Gill D, Thompson DR, et al. Depression and anxiety as predictors of outcome after myocardial infarction. Psychosom Med. 2000;62:212-9.

28. Brink E, Karlson BW, Hallberg LR. Health experiences of first-time myocardial infarction: factors influencing women's and men's health-related quality of life after five months. Psychol Health Med. 2002;7: 5-16.

29. Martin CR, Lewin RJ, Thompson DR. A confirmatory factor analysis of the Hospital Anxiety and Depression Scale in coronary care patients following acute myocardial infarction. Psychiatr Res. 2003;120:85-94.

30. Efron B, Tibshirani R. The bootstrap method for assessing statistical accuracy. Behaviormetrika. 1985;17:1-35.

31. Platt RW, Hanley JA, Yang H. Bootstrap confidence intervals for the sensitivity of a quantitative diagnostic test. Stat Med. 2000;19:313-22.

32. Hochberg Y. A sharper Bonferroni procedure for multiple tests of significance. Biometrika. 1988;75:800-3.

33. Schleifer SJ, Macari-Hinson MM, Coyle DA, et al. The nature and course of depression following myocardial infarction. Arch Intern Med. 1989; 149:1785-9.

34. Carney RM, Freedland KE, Jaffe AS. Insomnia and depression prior to myocardial infarction. Psychosom Med. 1990;52:603-9.

35. Forrester AW, Lipsey JR, Teitelbaum ML, DePaulo JR, Andrzejewski PL. Depression following myocardial infarction. Int J Psychiatr Med. 1992;22:33-46.

36. Lesperance F, Frasure-Smith N, Talajic M. Major depression before and after myocardial infarction: its nature and consequences. Psychosom Med. 1996;58:99-110.

37. Watkins LL, Blumenthal JA, Carney RM. Association of anxiety with reduced baroreflex cardiac control in patients after acute myocardial infarction. Am Heart J. 2002;143:460-6.

38. Berkman LF, Blumenthal J, Burg M, et al. Effects of treating depression and low perceived social support on clinical events after myocardial infarction: the enhancing recovery in coronary heart disease patients (ENRICHD) randomized trial. JAMA. 2003;289:3106-16.

39. Lane D, Carroll D, Ring C, Beevers DG, Lip GY. The prevalence and persistence of depression and anxiety following myocardial infarction. $\mathrm{Br}$ J Health Psychol. 2002;7:11-21.

40. Luutonen S, Holm H, Salminen JK, Risla A, Salokangas RK. Inadequate treatment of depression after myocardial infarction. Acta Psychiatr Scand. 2002;106:434-9.

41. Barefoot JC, Burg MM, Carney RM, et al. Aspects of social support associated with depression at hospitalization and follow-up assessment among cardiac patients. J Cardiopulm Rehabil. 2003;23:404-12.

42. Lauzon C, Beck CA, Huynh T, et al. Depression and prognosis following hospital admission because of acute myocardial infarction. CMAJ. 2003; 168:547-52.

43. Taylor CB, Houston-Miller N, Ahn DK, Haskell W, DeBusk RF. The effects of exercise training programs on psychosocial improvement in uncomplicated postmyocardial infarction patients. J Psychosom Res. 1986;30:581-7.

44. Davis T, Jensen L. Identifying depression in medical patients. Image $J$ Nurs Sch. 1988;20:191-5.

45. Silverstone PH. Changes in depression scores following life-threatening illness. J Psychosom Res. 1990;34:659-63.

46. Gilutz H, Bar-On D, Billing E, Rehnquist N, Cristal N. The relationship between causal attribution and rehabilitation in patients after their first myocardial infarction. A cross cultural study. Eur Heart J. 1991; 12:883-8.

47. Legault SE, Joffe RT, Armstrong PW. Psychiatric morbidity during the early phase of coronary care for myocardial infarction: association with cardiac diagnosis and outcome. Can J Psychiatr. 1992;37:316-25. 
48. Steeds RP, Bickerton D, Smith MJ, Muthusamy R. Assessment of depression following acute myocardial infarction using the Beck Depres sion Inventory. Heart. 2004;90:217-8.

49. Garcia L, Valdes M, Jodar I, Riesco N, de Flores T. Psychological factors and vulnerability to psychiatric morbidity after myocardial infarction. Psychother Psychosom. 1994;61:187-94.

50. Travella JI, Forrester AW, Schultz SK, Robinson RG. Depression following myocardial infarction: a one year longitudinal study. Int J Psychiatr Med. 1994:24:357-69.

51. Strik JJ, Honig A, Lousberg R, Denollet J. Sensitivity and specificity of observer and self-report questionnaires in major and minor depression following myocardial infarction. Psychosomatics. 2001; 42:423-8.

52. Lesperance F, Frasure-Smith $\mathbf{N}$, Theroux $\mathbf{P}$, Irwin $\mathbf{M}$. The association between major depression and levels of soluble intercellular adhesion molecule 1 , interleukin-6, and C-reactive protein in patients with recent acute coronary syndromes. Am J Psychiatr. 2004;161: 271-7.

53. Trelawny-Ross C, Russell O. Social and psychological responses to myocardial infarction: multiple determinants of outcome at six months. J Psychosom Res. 1987;31:125-30.

54. Follick MJ, Gorkin L, Smith TW, Capone RJ, Visco J, Stablein D. Quality of life post-myocardial infarction: effects of a transtelephonic coronary intervention system. Health Psychol. 1988;7:169-82.

55. Clarke DE, Walker JR, Cuddy TE. The role of perceived overprotectiveness in recovery 3 months after myocardial infarction. J Cardiopulm Rehabil. 1996;16:372-7.

56. Lehto S, Koukkunen H, Hintikka J, Viinamaki H, Laakso M, Pyorala K. Depression after coronary heart disease events. Scand Cardiovasc J. 2000;34:580-3.

57. Shiotani I, Sato H, Kinjo K, et al. Depressive symptoms predict 12 month prognosis in elderly patients with acute myocardial infarction. $J$ Cardiovasc Risk. 2002;9:153-60.

58. Blazer DG, Kessler RC, McGonagle KA, Swartz MS. The prevalence and distribution of major depression in a national community sample: the National Comorbidity Survey. Am J Psychiatr. 1994;151: 979-86.

59. Burvill PW. Recent progress in the epidemiology of major depression. Epidemiol Rev. 1995;17:21-31.
60. Burvill PW, Johnson GA, Jamrozik KD, Anderson CS, Stewart-Wynne EG, Chakera TM. Prevalence of depression after stroke: the Perth community stroke study. Br J Psychiatr. 1995;166:320-7.

61. Robinson RG, Starr LB, Price TR. A two year longitudinal study of mood disorders following stroke. Prevalence and duration at six months followup. Br J Psychiatr. 1984;144:256-62.

62. Cassidy E, O'Connor R, O'Keane V. Prevalence of post-stroke depression in an Irish sample and its relationship with disability and outcome following inpatient rehabilitation. Disabil Rehabil. 2004;26:71-7.

63. Astrom M, Adolfsson R, Asplund K. Major depression in stroke patients. A 3-year longitudinal study. Stroke. 1993;24:976-82.

64. Kurlowicz LH, Streim JE. Measuring depression in hospitalized, medically ill, older adults. Arch Psychiatr Nurs. 1998;12:209-18.

65. Koenig HG, Cohen HJ, Blazer DG, Krishnan KR, Sibert TE. Profile of depressive symptoms in younger and older medical inpatients with major depression. J Am Geriatr Soc. 1993;41:1169-76.

66. Koenig HG, George LK, Peterson BL, Pieper CF. Depression in medically ill hospitalized older adults: prevalence, characteristics, and course of symptoms according to six diagnostic schemes. Am J Psychiatr 1997; 154:1376-83.

67. American Psychiatric Association. Diagnostic and Statistical Manual of Mental Disorders. 4th ed. Washington, DC: American Psychiatric Association; 1994.

68. Snaith RP. The Hospital Anxiety and Depression Scale. Health Qual Life Outcomes. 2003;1:29.

69. Ruo B, Rumsfeld JS, Hlatky MA, Liu H, Browner WS, Whooley MA. Depressive symptoms and health-related quality of life: the heart and soul study. JAMA. 2003;290:215-21.

70. Serebruany VL, Glassman AH, Malinin AI, et al. Enhanced platelet/ endothelial activation in depressed patients with acute coronary syndromes: evidence from recent clinical trials. Blood Coagul Fibrinolysis 2003; 14:563-7.

71. Ziegelstein RC, Fauerbach JA, Stevens SS, Romanelli J, Richter DP Bush DE. Patients with depression are less likely to follow recommendations to reduce cardiac risk during recovery from a myocardial inf arction. Arch Intern Med. 2000;160:1818-23.

72. Glassman AH, O'Connor CM, Califf RM, et al. Sertraline treatment of major depression in patients with acute MI or unstable angina. JAMA 2002;288:701-9.

\section{Supplementary Material}

The following supplementary material is available for this article online:

\section{Appendix A: Literature Search Strategies.}

Appendix B: Journals Included in Hand Searching. 